\title{
History of Development and Concept of Person-Centered Counseling in Cultural Diversity
}

\author{
Hadi Warsito Wiryosutomo', Farida Hanum², Siti Partini ${ }^{3}$
}

\begin{tabular}{l} 
ARTICLE INFO \\
\hline Article History: \\
Received 01.09.2018 \\
Received in revised form \\
01.11 .2018 \\
Accepted \\
Available online 01.01 .2019
\end{tabular}

Available online 01.01.2019

\begin{abstract}
This study aims to obtain knowledge about two things; (1) how the development history of personcentered counseling, and (2) how the concept of person-centered theory in cultural diversity. This article contains a theory review regarding the history of the development of the theory of counseling person-centered and the concept of the theory in the diversity of culture of counseling and cultural diversity in schools. Person-centered counseling is the third generation of counseling models developed by Rogers. This model is more person-centered, emphasizing the need for experts who provide counseling (counselors) to involve aspects of their own personality and personality aspects of the counseled party (counselee) in the counseling process. Person-centered counseling also emphasizes the affective aspects of the individual, has a positive outlook on human nature.
\end{abstract}

Keywords: ${ }^{1}$

(C) 2019 IJERE. All rights resenved

Counseling, cultural diversity, person-centered

\section{INTRODUCTION}

During the late decades of the 20th century, the multicultural counseling competence movement emerged as a primary topic of concern in the helping professions, acquiring the status of a "fourth force" in counseling and psychology, and the training and practice of the culturally competent counselor have proliferated the field (Quinn, 2012). According to him, in a general sense the competence of multicultural counseling refers to high skills to help individuals, families, groups, or communities who are under pressure due to acts of discrimination or oppressive practices carried out by members or groups that are dominant in a particular culture. The concept of multicultural counseling develops when counseling practitioners experience obstacles when helping counselees who come from or have different cultural backgrounds. This difference creates its own conflict in the counseling process when aspects of counselee behavior are not easily understood by counselors. This counselor's difficulty is rooted in the differences in cultural background between himself and the counselee. Multicultural counseling arises and develops as a strategy to deal with these difficulties which arise from the differences in culture between counselees and counselors. In the counseling literature, both in the form of textbooks and journals, counseling theories and practices that accommodate the cultural diversity of counselees are commonly referred to as multicultural counseling (multicultural counseling). The development of multicultural counseling is also triggered by the aw areness of clinical experts that all individuals are in a social, political, historical and economic context which all affect individual behavior (APA, 2002). The context and influence on individual behavior cause diversity.

Cillier (2004) suggested several concepts of diversity. According to him, diversity refers to the mix or differences and similarities between individuals and groups, such as age, gender, race, ethnicity, or cultural background that form a social identity. It can be said that multicultural counseling needs to pay attention to the social identity of the counselee. according to its diversity, the social identity can be specified into specific identities, such as gender, sexual, and national identity (Benwell, and Elizabeth. 2006). Based on this understanding, multi-cultural counseling can be interpreted as a counseling activity that pays attention to and accommodates diversity which was formed by cultural differences in counselor and counselee relationships. In the context of organizational behavior, diversity refers to a number of individual variables that affect a task or relationship. This means that diversity has an impact on results and services that are developed through personal, interpersonal, organizational and workshops activities.

Cillier (2004) also proposes two primary and secondary dimensions of diversity. Primary dimensions relate to individual characteristics that cannot be easily changed, such as age, sex, and rass, physical

\footnotetext{
${ }^{1}$ Corresponding e-mail: hadiwarsito@unesa.ac.id, orcid.org/0000-0002-2680-3800 Universitas Negeri Yogyakarta ${ }^{1,2,3}$
} 
appearance or nature, and sexual orientation. This dimension will shape self-image and influence individuals in seeing the world. The greater the primary dimension difference between individuals, the more difficult it is to develop trust and respect or satisfying interpersonal relationships. Secondary diver sity dimensions are relatively individual attributes that can be changed or modified, such as communication styles, education, marital status, religious beliefs, work experience, and income. This dimension adds to the complexity of the individual self-image. The interaction between primary and secondary dimensions will shape individual values, priorities, and perceptions. Effective relationships between individuals will be possible if differences can be accepted.

Whereas culture is defined as a value orientation and belief system that affects social customs, norms, practices, and institutions, including psychological processes (language, media, education system) and organization (media, education system) (APA, 2002). Inherent in this definition is the recognition that all individuals are cultural beings and have racial, ethnic, and cultural heritage. Culture has been described as an embodiment of worldviews through beliefs and values learned and transmitted, and practices, including religious and spiritual traditions. It also includes ways of life that are informed by historical, economic, ecological, and political forces in a group. These definitions show that culture is fluid and dynamic and that there are universal cultural phenomena and certain or relative cultural constructions (APA, 2012).

Based on that understanding and on the spirit that counseling is an effort to help individuals meet their needs and that individuals are unique, multicultural counseling is very suitable to be applied in a country that has wide cultural diversity, such as in Indonesia. As stated by Lebauf et al. (2009) that multicultural counseling was chosen and carried out if counselors and counselees belonged to different cultural groups, and this counseling model became a much-sought approach by counselors who practice in a country that has a wide variety of cultures. Further stated by LeBauf et al. that multiculturalism has been seen as the fourth force in the helping profession. Other strengths include psychodynamic, humanistic, cognitive, and behavioral approaches. It is important for the counselor that he must accurately understand the behavior of the counselee and that behavior is shaped by a number of variables, one of which is culture. Therefore, he must understand the counselee's cultural background and adapt his strategic approach to the cultural background of the counselee. Even so, person-centered counseling cannot always be applied as a multicultural counseling, especially in populations with eastern cultural backgrounds. As stated by Wang (2003) that from his clinical experience he found the ineffectiveness of using Rogerian counseling in populations with eastern culture (Taiw an) (Chun-Chuan Wang, 2003).

Although some experts have proposed a theoretical model of multicultural counseling, some major counseling theories (mainstream) basically have elements and can be used as a framew ork for multicultural counseling (see Corey, 2009). Among these main theories, personal-centered counseling is not getting the attention of multicultural counselors. Initially, there were no research results that proved the effectiveness of personal-centered counseling to deal with cultural performance, but recent research in the 21st century conducted in countries such as Brazil, Malaysia, Iran, and the United States provided empirical evidence that supported the effectiveness of person-centered counseling as an effective and equivalent treatment for culturally diverse populations (Quinn, 2012).

Person-centered counseling in cultural diversity is essentially an application of person-centered counseling to help counselees with diverse cultural backgrounds. Therefore, the application of counseling person-centered in cultural diversity is basically the application of multicultural person-centered counseling.

Person-centered counseling is counseling model that emphasizes the need for experts who provide counseling (counselors) to involve aspects of their own personality and personality aspects of the counseled person (counselee) into the counseling process. So the counselor needs to understand and appreciate the unique aspects of the counselee's personality in addition to involving his own aspects of personality in the counseling process. This counseling model was developed by Carl Ransom Rogers - often called Carl Rogers and his followers (called Rogerian) (Cormier, 2008) and therefore also often referred to as the Rogerian Counseling model.

In the counseling and psychotherapy literature (Corey, 2009; Sharf, 2012) person-centered counseling is grouped into affective-humanistic approaches because it emphasizes the affective/emotional aspects of individuals having a positive view of human nature. The first generation of counseling model developed by Rogers was known as "nondirective counseling" which was developed around 1942. This counseling model directs the role of counselors who tend to be passive, in the sense that they only encourage counselees to 
open themselves (telling the difficulties to experience it, listen actively, and then reflect what the counselee communicates. The second generation counseling model is Client-centered counseling, which is an improvement of the first generation counseling model.

In person-centered counseling, counselor not only reflects the messages communicated by the counselee but also the implicit emotions or feelings that accompany the counselee's message so that the counselee becomes more actualized and becomes a fully functional person. Counselors also encourage counselees to take greater responsibility - even fully - on the counselee to solve his difficulties or direct himself (Corey, 2009). This model is what then underlies the emergence of the concept of empathy skills (Cormier, Nurius, \& Osborn, 2009). In person-centered counseling, counseling is construed as an active partnership between two persons, namely the counselor's personal and the counselee's personal (Cormier, Nurius, \& Osborn, 2009). This model emphasizes development - Rogers calls development with the term counselee's personal growth by experiencing himself and experiencing others in relationships. This model also emphasizes the need for the counselor to work hard to understand the personal aspects of the counselee and then accept and appreciate it as a unique person, in addition to displaying his own personality as a whole and authentic (Corey, 2009). The counselor needs to involve his own personal aspects in the process of impregnating the relationship that he not only accepts and appreciates the actions of the counselee that is not in line with his expectations, but also must recognize if in the counseling process he experiences negative emotions, such as disappointment, anger, not patient, and physically feeling tired. However, even though the counselor acknowledges that he experiences negative emotions, that does not mean that he may leave his counsel. His willingness to help counselees must be sincere and sincere (authentic) as long as the counselee still wants it.

Although the counseling model developed by Rogers has undergone evolution and change, the three fundamentally remain based on the same assumption, namely that each individual has an inherent drive to actualize himself (Cormier, Nurius, \& Osborn, 2009). This tendency can be realized if individuals obtain conditions - both inside and outside the context of counseling - that can facilitate this tendency.

\section{Aim of the Study}

This study aims to obtain knowledge about three things, namely what are the principles of personcentered counseling in the cultural diversity of the counselee; implementation of person-centered counseling services in cultural diversity; and the pattern of trends in its implementation. This article contains a theoretical study regarding this matter.

\section{METHOD}

This article is included in the literature studies. Literature review is a description of the theory, findings, and other research material obtained from reference material to be used as the basis for research activities to develop a clear frame of mind from the formulation of the problem to be studied. In another source said, literature review is an analysis in the form of criticism (build or drop) of research being carried out on specific topics or questions about a part of science. Literature review is a scientific story about a particular problem. The method used is to find a theory reference with the case or problem found. After conducting preliminary research, the researcher studying some relevant literature, about person-centered counseling.

\section{FINDINGS}

\section{History of Development of Person-centered Counseling}

Person-centered counseling focuses on personal counselees. The counselor needs to understand and appreciate the unique aspects of the counselee's personality in addition to involving his own aspects of personality in the counseling process. This counseling model was developed by Carl Ransom Rogers - often called Carl Rogers - and his followers (called Rogerian) (Cormier, 2008) and therefore also often referred to as the Rogerian Counseling model. In the counseling and psychotherapy literature (Cor ey, 2009; Sharf, 2012) person-centered counseling is grouped into affective-humanistic approaches because it emphasizes the affective/emotional aspects of individuals having a positive view of human nature.

Person-centered counseling is basically a third generation counseling model developed by Rogers and his followers (Cormier, Nurius, \& Osborn, 2009; Sharf, 2012). The first generation of counseling model developed by Rogers was known as "nondirective counseling" which was developed around 1942. This 
counseling model directs the role of counselors who tend to be passive, in the sense that they only encourage counselees to open themselves (telling the difficulties to experience it, listen actively, and then reflect what the counselee communicates. The second generation counseling model is Client-centered counseling, which is an improvement of the first generation counseling model. In this model, the counselor not only reflects the messages communicated by the counselee but also the implicit emotions or feelings that accompany the counselee's message so that the counselee becomes more actualized and becomes a fully functional person. Counselors also encourage counselees to take greater responsibility - even fully - on the counselee to solve his difficulties or direct himself (Corey, 2009). This model is what then underlies the emergence of the concept of empathy skills (Cormier, Nurius, \& Osborn, 2009).

In person-centered counseling, counseling is construed as an active partnership between two individuals, namely the counselor's personal and the counselee's personal (Cormier, Nurius, \& Osborn, 2009). This model emphasizes development, Rogers calls development with the term growth, personal counselee by experiencing himself and experiencing others in relationships. This model also emphasizes the need for the counselor to w ork hard to understand the personal aspects of the counselee and then accept and appreciate it as a unique person, in addition to displaying his own personality as a whole and authentic (Corey, 2009). The counselor needs to involve his own personal aspects in the process of impregnating the relationship that he not only accepts and appreciates the actions of the counselee that is not in line with his expectations, but also must recognize if in the counseling process he experiences negative emotions, such as disappointment, anger, not patient, and physically feeling tired. However, even though the counselor acknowledges that he experiences negative emotions, that does not mean that he may leave his counsel. His willingness to help counselees must be sincere and sincere (authentic) as long as the counselee still wants it.

When Rogers developed a first-generation counseling model, non-directive counseling, the practice of counseling at that time was dominated by a psychoanalytic and behavioral approach. Rogers was dissatisfied with the existing counseling model because he thought it was inadequate (Corey, 2009; Sharf, 2012; Thorne, 2003). Rogers (Sharf, 2012) views the psychoanalytic and behavioral couns eling model as a less scientific treatment system because it places the counselor as an expert, namely placing the counselor as an expert, in the sense that he is the person who knows best about the counselee's problems and can direct the counselee to what should be done by the counselee. Rogers also disagrees with the psychoanalytic paradigm that emphasizes diagnostic and interpretation methods. Rogers views psychoanalytic and behavioral methods as not being able to encourage optimal grow th in counselees.

According to Cormier, Nurius, \& Osborn (2009), many experts have recently proposed a counseling model that integrates person-centered counseling with cognitive behavioral strategies or other models that have obtained empirical support. In this model, the counselor communicates three facilitative conditions while applying various types of counseling techniques or strategies. As stated by Tursi \& Cohran (2006) that cognitive-behavioral tasks can occur naturally (natural) in person-centered counseling and know ledge of behavioral counseling theories and strategies can improve counselor empathy. The proposed integration model is basically intended to give respect to the view of convergence to support the effectiveness of the application of core conditions to achieve the results (objectives) of counseling, in addition to giving the counselor the freedom to do many actions to meet the diversity of needs or desires of the counselee. In principle, experts who propose this integration approach have the view that the incorporation of the relationship/application of the core conditions of counseling and counseling strategies/techniques will more effectively achieve the achievement of counseling goals.

\section{Concept of Person-Centered Counseling in Cultural Diversity}

The theory of person-centered counseling developed by Rogers is based on the personality theory that he developed previously coupled with his experience in clinical practice. Here are some psychological concepts put forward by Rogers in the personality theory that he developed and then used as a conceptual framew ork in formulating counseling theories.

\section{Self-actualization}

Rogers has more humanistic (humane) view than experts from psychoanalytic and behavioral theory. According to Rogers (Corey, 2009), individuals are not creations that have been determined by innate (deterministic) as believed by psychoanalysts, or as creatures that adhere to environmental influences as 
believed by experts behavior (behaviorists). Instead, he has the belief that every human being has positive potential and inherent skills to direct himself to act positively and constructively (Corey, 2009; Cormier, Nurius, \& Osborn, 2009; Sharf, 2012). However, this potential often cannot be realized (realized) because they are in an environment that does not support or facilitate the realization of this potential.

In more detail, Rogers (Corey, 2009; Sharf, 2012) asserts that each individual is basically trustworthy, has a lot of potentials (resourceful), is capable of self-understanding and directs himself (self-direction ) They are also able to make constructive changes and have the ability to be effective and productive human beings in their lives. Then what causes individuals to display deviant behavior and take actions that are contrary to the demands of society? According to Rogers (Corey, 2009) various forms of negative and destructive actions, such as aggressive, are not rooted in the inherent nature of human beings, but a form of self-defense attitude (self-defense mechanism) that encourages (excludes) individuals from their inherent nature. If this defense attitude is reduced, then the individual will become more open to all his experiences, be trustw orthy, and can act adaptively (constructively) according to the demands of his environment.

Rogers also has the belief that since his birth the individualbrings the tendency to actualizing tendency, namely a tendency to develop all the potential or abilities possessed in order to maintain and improve the quality of oneself (Corey, 2009; Sharf, 2012). This tendency is the ability inherent in the individual and becomes a source (strength) for individuals to handle every difficulty and achieve positive growth, and allows individuals to form more adaptive behavior (distance themselves from behavior that is not in line with environmental expectations. therefore it can be said that from birth individual has brought the potential to be a healthy human because he has the ability to handle various forms of difficulties in his life. Roughly this tendency can be described as an inherent effort in every human being to achieve growth, health, adjustment Optimal socialization, self-realization and autonomy The tendency to self-actualize is believed to be a single motive that is innate and inherent in each individual and moves individuals to struggle to care for themselves and realize all their potential. Rogers (Corey, 2009) uses the term fully functioning person to describeindividuals who can actualize themselves, namely people who can optimally use all their potential.

The tendency to self-actualize has two aspects, biological and psychological (Rykman, 2008). The biological aspect contains the impulses to satisfy basic living needs, namely the need for water, air, and food. While the psychological aspects include the development of potential that makes individuals more valuable human beings. This positive view of human nature needs to be applied by counselors in counseling relationships. In this case, Rogers emphasizes that counseling relationships are essen tial in influencing the success of counseling. As stated (Corey, 2009), counseling counselors must display humanistic behavior, because counseling relationships should be a humanist assistance process or emphasize the principles of humanism. Humanism is an attitude or way of thinking that puts other people (people) as beings who have positive potential and need to be appreciated. Humanism is "... a style of thought or attitude that makes human central, important, valuable, crucial, pivotal, w onderful, pow er ful - even miraculous (Barton, 1992: 332). So humanist counselors are those who have a thinking and acting style that puts the counselee as an individual who needs to be the center of attention (heard), valuable, very important, great, capable - even magical. In the counseling process, the counselor must accept and respect the personal rights of the counselee and the assets that the counselee brings to the counseling process. The counselee will probably make positive changes if the counselor is able to experience and communicate reality (realness), support (support), love/care (caring), and sincere understanding.

Rogers summarized various forms of humanist characteristics into three attributes of counselor attitudes that can form a relationship climate that can encourage counselee growth, namely: (1) empathic and accurate understanding (accurate emphatic understanding) which implies that counselors are able to accurately capture the subjective world counselee; (2) congruence (congruence) which implies or cont ains sincerity or sincerity to help / help (genuineness); and (3) unconditional positive regard, which implies that the counselor must accept and respect the uniqueness of the counselee without applying an assessment of the counselee's behavior (Corey, 2009; Cormier, Nurius, \& Osborn, 2009; Sharf, 2012).

\section{Subjective perception}

The humanistic approach used by Rogers is based on phenomenological theory, which emphasizes the subjective perception of individuals on the reality or events they experience. According to the phenomenological view, the reality is not an objective realization of something or event but what is 
perceived by individuals subjectively. In other words, the reality exists in the world of subjective experience or individual personal experience (Corey, 2009; Cormier, Nurius, \& Osborn, 2009; Sharf, 2012). The phenomenological view also emphasizes that each individual will act according to his perception. This view confirms that what is done by an individual when he responds to a situation in the surrounding environment is always consistent $w$ ith his perception of the situation at hand. This perception is subjective in the sense that what is perceived by the individual is in accordance with the terms of reference (the mindset) which is held by itself and not based on objective reality. Because of its subjective nature, the way individuals respond to a situation may be different from others. So, two individuals who face the same event can form different perceptions and then experience it differently. Whether an event is experienced as pleasant or painful depends on how the individual perceives it.

The implication of the phenomenological view in counseling practice is that the counselor needs to understand the counselee's problems in accordance with the counselee's subjective perception or the counselee's internal terms of reference. The counselor does not apply a specific assessment regarding what is experienced by the counselee. The counselor must develop a humanistic relationship by accepting and appreciating any form of counselee's perception of an event and how it experiences it, even if the perception is biased or not in accordance with its objective reality and he experiences it in an excessive way. To understand what is a true subjective reality in the phenomenological framew ork can be seen in what Schultz \& Schultz (2008: 329) follows:

The notion that perception is subjective is an old one and not unique to Rogers. This idea, called phenomenology, argues that the only reality of which we can be sure is our own subjective world of experience, our inner perception of reality. The phenomenological approach within philosophy refers to an unbiased description of our conscious perception of the world, just as it occurs, without any attempt on our part at interpretation or analysis. In Rogers's view, the most important point about our world of experience is that it is private and thus can only be known completely to each of us.

Rogers's phenomenological view is rooted in his belief that individuals interpret reality not objectively but based on their own experiences and perceptions (called subjective perception). So, the reality of an event or experience is subjective (in accordance with individual perceptions) and not objective. Rogers (Sharf, 2012; Thorne, 2003) has the belief that subjective reality is more important than objective reality in influencing behavior. Therefore, the best way to understand individual behavior is by knowing the individual's subjective perception of him, the events he experiences, and the environment in which he grows and develops. The implication is, if the counselor wants to succeed in helping the counselee, he can understand the counselee's subjective world or the way in which the counselee perceives the situation or events he experiences. The counselor manages to help the counselee if he can make the counselee into a person who is more open to experience (open to the experience) without distorting or denying it. Although Rogers believes in the importance of the counselee's subjective world in influencing behavior, he acknowledges the limitations of examining individual subjective experiences (White et al., 2013). Therefore he wants his theoretical formulation to be verified through scientific research. Rogers' phenomenological view contains several psychological concepts or constructs that he uses to describe the development of individual behavior, influencing factors, and their application in counseling or psychotherapy theories.

\section{Positive regard and self-esteem}

Every individual has a tendency to actualize himself, not all individuals can make it happen successfully. The success of an individual in actualizing himself is influenced by environmental conditions that support the realization of this tendency in the form of positive rew ards without unconditional positive regard from those around him (Corey, 2009; Sharf, 2012). The need for positive appreciation is increasing following the development of his age. Meeting these needs is influenced by individual interactions with good people around them. That is, individuals can get positive rewards if they often interact with other people who can give positive rewards.

Fulfillment of the need for self-esteem is often not objective but is based more on the subjective perception of individuals on internal and external reality (Sharf, 2012). Therefore, it is important for people around the lives of individuals to show such treatment to individuals that they perceive that people around them can receive and appreciate it without applying certain judgments. If the individual perceives that he is not accepted, he is valued (rejected), then he experiences a servitude to actualize himself. In order to 
actualize himself, the individual must perceive that the people around him can accept his presence/presence, pay attention to him, respect his opinion, love and love him, care for him. Therefore, if an individual (counselee) does not receive or experience positive appreciation from his parents at home or from his friends, it is very important for counselors at school to satisfy those needs.

Rogers (Sharf, 2012) says that the individual's perception of the positive rew ards he receives from others has a direct impact on the development of his self-esteem (self-regard). If children perceive that people around them (parents, teachers, friends) accept and respect themselves, then the child will develop a positive/ valuable feeling about him (a sense of self-worth) or positive self-esteem (self-regard) . Likewise, individuals who perceive that they are recognized, accepted, or valued by those around them will experience a degree of optimal psychological functioning and this condition causes individuals to be more likely to develop a healthy personality, display adaptive behavior, can actualize themselves optimally.

\section{Growth conditions}

Although positive appreciation from the environment is an important and sufficient condition to encourage individual grow th and facilitate the struggle to achieve self-actualization, not every individual can get it easily. According to Rogers (Corey, 2009; Sharf, 2012), some individuals are in an environ ment that gives conditional appreciation, which is conceptualized as a form of grow th condition (condition of grow th). Growth conditions are defined as a process of evaluating a personal experience based on the beliefs or judgments of others. This condition can limit or inhibit individual development, causing individuals to experience incongruence between personal experiences of themselves and their interactions with others. This inconsistency has the potential to damage self-concept and causes behavioral disturbances. In Rogers' phenomenological perspective, self-concept is an important aspect that influences personality development.

The condition of the award implies that to get a positive award, the individual must meet certain conditions or conditions. To obtain the conditional positive aw ard, the individual must fulfill what is desired by others and ignore his personal interests or experiences (Corey, 2009). So, the child may be forced to ignore his own values or beliefs and do what is ordered by parents so that he gets attention or love from his parents. When individual experiences several conditions of appreciation, he can lose touch with himself, and can even feel alien with himself. In other words, individuals experience inconsistencies in themselv es. The emergence of feelings of anxiety can be one indicator that individuals experience inconsistencies.

To resolve several conditions of appreciation that are applied by the environment, individuals develop a self-defense mechanism in the form of distortion and denial (Corey, 2009; Sharf, 2012). Individuals can distort or deny reality or experience. Individuals who use self-defense mechanisms imply that they are not open or do not want to accept their experiences. He refuses or denies it. This self-defense mechanism is used to protect the ego or self-concept. For example, students who get low scores on an exam, state that they are not good at doing exam questions because they happen to have learned the wrong material (refraction), or say because the teacher is unfair or evil (deny). The use of self-defense mechanisms, in addition to causing individuals to become less or inaccurate in perceiving the environment, also causes individuals to experience psychological disorders. Because, in the phenomenological concept, healthy people are people who are open or willing to accept all their experiences. Rogers (Sharf, 2012) also suggested several other forms of selfdefense mechanisms, namely: rationalization, fantasy, projection, and paranoid thinking. Rationaliza tion is the most common mechanism. For example, a school counselor who sees himself as a "competent mentor" but what he experiences is that "many students avoid when he wants to provide guidance." Then he made a rationalization, "Children who avoid me are those who feel they have no problems. "In this case, there is a conflict betw een self-view and experience.

\section{Healthy person}

Rogers (Corey, 2009; Sharf, 2012) describes healthy individuals or individuals who have healthy personalities who are able to actualize themselves. Rogers (Corey, 2009; Rykman; 2008; Sharf, 2012) mentions individuals who can actualize themselves are those who can empower or realize all their potential optimally. and become a fully functioning person. Individuals who can actualize themselves and become fully personal are the images of healthy people. Rogers (Corey, 2009; Rykman, 2008; Sharf, 2012) describes several characteristics of individuals who actualize themselves, including; first, open to experience. Individuals who self-actualize are those who are not defensive - use self-defense mechanisms to refract or deny experience. They can accept (open) all forms of feelings they experience - fear, hate, anger, disappointment, anxiety, 
passion - and can realize and accept all their experiences, both pleasant and unpleasant. Second, showing existential life. Individuals who actualize themselves can experience all experiences in the current situation, have meaning and purpose in life, namely having a clear direction in their lives and always trying to do things that are meaningful both for themselves and others. Third, able to trust him. Individuals who actualize themselves can trust their abilities, namely having the belief that they have the skills and positive things that are communicated by others.

Rogers (Sharf, 2012) also characterizes individuals who are open to experience. According to him, individuals who are open to experience tend to be creative and responsible. Openness to experience allows individuals to deal with past and current situations (new situations) creatively. Through this adaptive ability, individuals will experience a freedom to make decisions and be the person responsible for their own lives. As part of a fully functional person, individuals are able to realize and fulfill social responsibilities and the need for truly congruent (authentic) relationships with others. They are not only aware of their own needs but also sensitive to the needs of others.

\section{RESULT, DISCUSSION, AND SUGGESTIONS}

First, around 1942 Rogers developed a nondirective counseling model. In this counseling model the role of the counselor tends to be passive, he only encourages the counselee to open himself (telling the difficulties experienced), listens actively, and then reflect on what the counselee communicates.

Second, Rogers developed a model 'Client-centered counseling. In this model, the counselor not only reflects the messages communicated by the counselee but the implicit emotions or feelings that accompany the counselee's message so that the counselee becomes more actualized and becomes a fully functional person. Counselors also encourage counselees to take greater responsibility, even fully, on the counselee to solve his difficulties or direct himself.

The third generation is a person-centered counseling model. Also referred to as Rogerians counseling because it was developed by Rogers and his followers. This model is more person-centered, emphasizing the need for experts who provide counseling (counselors) to involve aspects of their own personality and personality aspects of the counseled party (counselee) in the counseling process. Person-centered counseling also emphasizes the affective/emotional aspects of individuals having a positive view of human nature.

Although the counseling model developed by Rogers has undergone evolution and change, fundamentally, all three remain based on the same assumption, namely that each individual has an inherent drive to actualize themselves (Cormier, Nurius, \& Osborn, 2009). This tendency can be realiz ed if individuals obtain conditions - both inside and outside the context of counseling - that can facilitate this tendency. In the context of the Branch Office, the counselee's grow th relates to three core conditions or facilitative conditions of the relationship in a high degree, namely: empathy (accurate understanding), genuineness or congruence, and positive regard or respect.) In his more recent w riting, Rogers (Cormier, Nurius, \& Osborn, 2009) asserts that empathy, sincerity, and positive appreciation are a set of skills in addition to the counselor's attitude. If these conditions are absent or not experienced by the counselee in a counseling relationship or in everyday life situations, the counselee can fail to achieve growth and even worse. These conditions are not only intended to be communicated by the counselor to the counselee but must also be perceived by the counselee in the same way. Cormier, Nurius, \& Osborn (2009) suggested the results of a study from Paulson, Truscott, \& Stuart published in 1999 which indicated that many counselees reported that these conditions were very helpful experiences for themselves in the overall counseling process. These three conditions are not experienced by the counselee separately but are interrelated between one another.

There are three attributes of counselor attitudes that can shape the relationship climate that can encourage counselee grow th, namely: (1) empathic and accurate understanding that implies that the counselor is able to accurately capture the counselee's subjective world; (2) congruence (congruence) which implies or contains sincerity or sincerity to help / help (genuineness); and (3) unconditional positive regard, which implies that the counselor must accept and appreciate the uniqueness of the counselee without applying an assessment of the counselee's behavior.

In person-centered counseling, individuals who cannot actualize themselves, or cannot handle obstacles to actualizing themselves, and become people who are not open to experience, have the potential to become people or develop unhealthy personalities. As stated by Rogers (Corey, 2009; Sharf, 2012) individuals will 
Wiryosutomo,H.W., Hanum,F. \& Partini,S. (2019).History of development and concept of person-centered counseling in cultural diversity. International Journal of Educational Research Review,4(1),56-64.

develop unhealthy personalities if they find obstacles in their struggle to actualize themselves, or if they are not open to experience when there is a wide gap between personal experience and self-view. In the teaching of self-concept or self, Rogers calls personal experience as actual self and self-view as ideal (self-ideal) (Corey, 2009; Sharf, 2012). The greater or wider the discrepancy between the individual's experience and his concept, causing the individual to be increasingly unable to control his behavior. The existence of conflicts that occur continuously between experience and view of the self can cause individuals to experience psychological disorders, and the wider the distance between experience and self-view causes individuals to experience psychosis. In this case, Rogers classifies behavior disorders in a continuum of severity according to the strength of distortion.

\section{REFERENCES}

American Psychological Association. (2002). Guidelines on multicultural education, training, research, practice, and organizational change for psychologists. [Online]. Available: http://www.apa.org/pi/oema/ resources/ policy/multiculturalguideline/... [Accessed: 19 January 2016]

Benwell, B. \& S. Elizabeth(2007). Discourse and Identity. Equinox Publishing, G\&L vol 1.2, pp. 315-318 [Online]. Available: http://equinox com. doi : 10.1558/genl.v1i2.315/...[Accessed: 17 January 2016]

Cilliers, F. (2004). A person-centered view of diversity In South Africa. The Person-Centered Journal, Vol. 11, No. 1-2, 2004. Printed in the United States. All rights reserved [Online]. Available: http://uir.unisa.ac.za/bitstream/handle/10500/18620/A20/...[Accessed: 17 January 2016].

Chun-Chuan W. (2003). Cultural influences vs. actualizing tendency: is the person-centered approach a universal paradigm? The Person-Centered Journal, Vol. 10. Printed In The Ll.S.A All Rights Reserved [Online]. Available: http://adpca.org/system/files/ documents/journal/...[Accessed: 29 December 2016]

Corey, G. (2009). Theory and practice of counseling and psychotherapy. Eighth Edition. USA: ThompsonWadsworth.

Corey, G. (2009). The art of integrative counseling. USA: Thompson - Brooks/Cole.

Cormier, S.; Nurius, P. S., \&. Osborn, C. J. (2009). Interviewing and change strategies for helpers. Fundamental Skills and Cognitive Behavioral Interventions. 6th. Ed. Belmont, CA: Brooks/Cole

LeBeauf, I.; Smaby, M. \& Maddux, C. (2009). Adapting counseling skills for multicultural and diverse clients. Paper based on a program presented at the 2009 American Counseling Association Annual Conference and Exposition, March 19-23, Charlotte, North Carolina. [Online] Available: https://www.counseling.org/Resources/Library/VISTAS/2009-V-Print/... [accessd: 27 May 2017]

Quinn, A. (2013). A person-centered approach to multicultural counseling competence. Journal of Humanistic Psychology, April . [Online]. Available: https://www.researchgate.net/publication/258151876. DOI: 10.1177/0022167812458452. [Accessed: 21 May 2017]

Rykman, R. M. (2008). Theories of personality. 9th. Ed. United States: Thompson-Wadsw orth.

Sharf, R. S. (1995). Theories of Psychotherapy and Counseling Concepts and Cases. 5th. Ed. USA: Brook/Cole - Cengage Learning.

Thorne, B. (2003). Carl Rogers. 2nd. Ed. London: Sage Publication 